\title{
Experience with the Histrelin Implant in Pediatric Patients
}

Erica A. Eugster, M.D., Department of Pediatrics, Riley Hospital for Children, Indiana University School of Medicine, Indianapolis, IN, USA

Short title: Histrelin implants in pediatrics

Address for correspondence:

Erica A. Eugster, M.D.

Pediatric Endocrinology \#5960

705 Riley Hospital Drive

Indianapolis, IN 46254

317 944-3889

317 944-3881 (fax)

eeugster@iu.edu

This is the author's manuscript of the article published in final edited form as:

Eugster, E. A. (2016). Experience with the Histrelin Implant in Pediatric Patients. In M. Cappa, S. Cianfarani, L. Ghizzoni, S. Loche, \& M. Maghnie (Eds.), Endocrine Development (Vol. 30, pp. 5459). S. Karger AG. Retrieved from http://www.karger.com/?doi=10.1159/000439330 


\begin{abstract}
The histrelin implant has emerged as a therapeutic option for the treatment of central precocious puberty (CPP) that has been favorably received by patients and providers. Inserted subcutaneously, the $50 \mathrm{mg}$ implant provides continuous release of the potent gonadotropin releasing hormone analog (GnRHa) histrelin. Profound suppression of the hypothalamic-pituitary-gonadal (HPG) axis occurs within one month of its placement resulting in pubertal arrest, attenuation of skeletal advancement and a progressive increase in predicted adult height. Although marketed for annual use, suppression lasting two years from a single implant has been demonstrated. Placing and removing the device is a minor outpatient procedure easily accomplished by a pediatric surgeon using local anesthesia. The major downside to the implant is a $\sim 25 \%$ rate of breakage upon removal. Information about recovery of the HPG axis following histrelin explanation is limited but suggests an average time to menarche comparable with depot-GnRHa formulations albeit with wide individual variation.
\end{abstract}


Introduction

The histrelin subcutaneous implant was approved for the treatment of central precocious puberty (CPP) in the US in 2007[1]. The implant, which is constructed of a flexible nonbiodegradable hydrogel, provides continuous release of the drug across microporous walls. The synthetic gonadotropin releasing hormone analog ( $\mathrm{GnRHa}$ ) histrelin is > 200 times more potent than native $\mathrm{GnRH}$ and has been commercially available for more than two decades[2]. However, because it previously required daily subcutaneous administration, histrelin became largely obsolete once monthly depot GnRHa preparations were developed [3]. Histrelin reemerged in the therapeutic armamentarium in the form of a yearly implant for the treatment of prostate cancer[4], which paved the way for studies in children with CPP[5]. Although the implants prescribed for these two indications both contain $50 \mathrm{mg}$ of drug, the device developed for children allows for a more rapid release of histrelin than the one used in adults $(65 \mathrm{mcg} / \mathrm{d}$ vs $41 \mathrm{mcg} / \mathrm{d})$. The device is inserted using a trocar, usually by a pediatric surgeon. Although the majority of centers perform the procedure using local anesthesia, conscious sedation and general anesthesia have also been utilized in select cases. Since its approval, the histrelin implant has rapidly increased in popularity in the United States and is now well-established as a highly efficacious treatment[6]. However, data regarding long-term follow-up of children treated with this modality are not yet available[7]. Treatment of Central Precocious Puberty

The first report of the use of the histrelin implant in children involved a pilot study of 11 girls with CPP, all of whom had previously been treated with a depot GnRHa preparation[8]. Serial GnRH stimulation tests demonstrated lower gonadotropin levels after insertion of the implant than on the depot GnRHa with continued HPG axis suppression throughout the treatment course. No 
difference in biochemical or clinical parameters was seen in patients in whom the implant was replaced at 9 months $(n=5)$ versus at 15 months $(n=6)$. Quality of life questionnaires found significantly lower rates of discomfort/pain and less disruption of activities during treatment with the implant than with depot GnRHa intramuscular injections. Following this small trial, an openlabel phase III multicenter study was undertaken that involved 36 children (3 boys) from 9 different centers, 20 of whom were naïve to GnRHa therapy. In both naïve and previously treated patients, peak stimulated LH significantly decreased within one month, and estradiol suppressed to prepubertal levels in naïve girls. Linear growth velocity and the ratio of bone age to chronological age (BA/CA) also declined during the initial year of treatment, while BMI percentiles remained stable [9]. Two year results in 31 children from this same trial demonstrated a further decline in peak stimulated LH at 24 months compared with 12 months as well as an increase in predicted adult height (PAH) of $5.1 \mathrm{~cm}[10]$. Final results from the extension phase of this multicenter study are now available. In children completing 6 years of treatment with sequential histrelin implants, pubertal suppression was maintained, BA/CA progressively decreased and PAH increased. The greatest gain was observed in treatment- naïve children, who experienced an increase of $10.5 \mathrm{~cm}$ in PAH at the end of the trial. No adverse effect on growth velocity or HPG axis recovery was seen, and the implant was well tolerated overall[11].

An important advance in the use of the histrelin implant for CPP was the demonstration that a single implant is effective for two years. This was based on the recognition that if $65 \mathrm{mcg}$ of drug is released each day, a $50 \mathrm{mg}$ implant should theoretically contain ample histrelin to maintain HPG suppression for 769 days, or exactly two years. That this is indeed the case was established by a study involving 33 children with CPP in whom a single implant was left in situ for two years. Peak stimulated LH at 12 and 24 months was equivalent whereas radiographic and 
clinical indices of puberty progressively improved[12]. Use of a single implant for two years has the distinct advantage of significantly decreasing cost and numbers of surgical procedures, and thus has become standard practice at many institutions (personal communication).

Surgical and Anesthetic Considerations

A systematic review of one surgeon's experience with histrelin implant procedures largely corroborates what has been reported in clinical trials. Of 114 cases, 50\% were implantations, $25 \%$ were explantations and $25 \%$ were removals followed by insertion of a new implant. The vast majority (95\%) of procedures were performed using local anesthesia, with general anesthesia employed primarily in neurologically-impaired children[13]. Inhaled nitrous oxide was utilized to augment local anesthesia in this series, although distraction using "child life" personnel is a less invasive and highly successful alternative approach (personal experience). At this author's institution, procedures involving the histrelin implant are also performed primarily by a single pediatric surgeon. Our surgeon reports an average duration of 16.6 minutes, although with a range of 3-55 minutes. A longer duration has been noted if the procedure is removal of an implant versus placement (21.6 minutes versus 10 minutes, $\mathrm{p}<0.0001$, unpublished data). Safety

Minor implant site reactions are the most common adverse event reported in patients treated with the histrelin implant and occur in $\sim 50 \%$ of patients. These are self-limited and resolve spontaneously. The most troubling safety concern associated with the implant has been a relatively high rate of implant breakage and or difficulty with localization. These issues are limited to the explantation procedure and appear to be due to encapsulation of the device or the presence of scar tissue. Anecdotally, implants appear to become quite desiccated and brittle in some children (personal communication) although individual patient characteristics that predict these problems 
have not been identified. Depending on the study, the rate of implant breakage ranges from 22$39 \%$ and is higher when left in place for two years. Other rarely reported complications have included infection, implant extrusion and keloid scar formation [5]. When intact or partial implants are difficult to localize due to fracture or migration from the insertion site, ultrasonography has been reported to be an effective modality to aid in the retrieval process[14].

Monitoring

The optimal strategy for monitoring therapy in children being treated for CPP has not been identified, and clinical practice varies significantly among providers. While there is general consensus regarding the importance of following clinical and auxological parameters such as Tanner staging, growth velocity and skeletal maturation, the role of routine hormonal measurements is controversial [15]. The shortage of synthetic GnRH in the US has led to alternative approaches for both the diagnosis and monitoring of children with CPP. One of these has been the use of random ultrasensitive LH values, which have been shown to correlate well with peak stimulated LH at the time of initial presentation [16]. Given the inherent appeal of a simpler and less invasive option than a full stimulation test, it is perhaps not surprising that random LH concentrations have also been applied to the monitoring arena. Interestingly, however, random LH has been shown to often remain in a pubertal range even in patients who have a fully suppressed HPG axis by every other criteria[17]. This phenomenon has been demonstrated during treatment with the histrelin implant as well as with depot leuprolide injections[18]. Thus, random ultrasensitive LH measurements do not have a place in the monitoring of children undergoing treatment for CPP. Whether any biochemical assessments aid in the management of children with CPP who are responding as expected to GnRHa treatment remains to be seen.

Recovery of the HPG Axis 
Limited information is available thus far regarding recovery of the HPG axis following treatment with the histrelin implant. In one study, time from explantation to menarche was determined in 11 girls, all but 2 of whom were previously treated with depot GnRHa injections, and was compared to 23 girls treated only with depot GnRHa. The average time to menarche was significantly shorter in the histrelin group compared with the injection group (9.3 vs 16 months, $\mathrm{p}=0.02)[19]$. In contrast, a larger study involving 30 girls with CPP found an average interval from implant removal to menarche of 12.75 months, albeit with significant individual variation. Of all variables analyzed, only older age at explantation correlated with a shorter duration to menarche. All boys experienced an increase in testicular volume within one year of cessation of histrelin implant therapy[20]. While a peak stimulated $\mathrm{LH}>4 \mathrm{mIU} / \mathrm{mL}$ is clearly indicative of reactivation of the reproductive system, there is evidence that free alpha subunit might represent the earliest detectable biochemical change following removal of the histrelin implant. Rising paradoxically during treatment, free alpha subunit concentrations have been shown to fall rapidly upon removal of the implant, preceding changes in sex steroids and gonadotropins by several weeks [21]. An additional advantage of this test is the ability to use it to determine whether an implant has been completely removed in cases where there has been breakage or difficulty with localization.

Future Directions

Many questions remain regarding the histrelin implant. In the short-term, the absolute upper-limit of efficacy of the device has not been established. While the implant clearly lasts for at least two years, continued suppression of the HPG axis beyond this is theoretically possible. A second logical question is whether the device could be altered in some way as to make breakage and/or problems with localization less of a problem. Additionally, although there are significant 
data regarding long-term follow-up of children treated with depot GnRHa [22], essentially no such information exists for the histrelin implant. Outcomes of interest include but are not limited to, reproductive function, bone mineral density and BMI. Whether CPP is associated with significant psychological problems and, if so, whether treatment with the histrelin implant or other GnRHa formulations alleviates these issues are also areas in which a deficit of knowledge exists[23]. Finally, it will be interesting to observe to what extent the histrelin implant is embraced as a therapeutic modality for CPP in Europe and other parts of the world as compared to its popularity in the US.

Conclusions

Although the histrelin implant is a relative newcomer to the cadre of GnRHa preparations for the treatment of CPP, studies conducted thus far have consistently demonstrated excellent efficacy of the device in terms of pubertal suppression, including when a single implant is left in place for two years. While generally well-tolerated, implant breakage and or problems with localization occur in approximately one fourth of patients at the time of removal. Large scale prospective studies will provide additional important information regarding efficacy, safety and long-term outcomes of children being treated with the histrelin implant for CPP. 


\section{Reference List}

1 Nebesio T, Eugster EA: The histrelin subdermal implant-a new treatment for children with central precocious puberty; 2007, pp 39-41.

2 Barradell LB, McTavish D: Histrelin. A review of its pharmacological properties and therapeutic role in central precocious puberty. Drugs 1993;45:570-588.

3 Brito VN, Latronico AC, Arnhold IJ, Mendonca BB: Update on the etiology, diagnosis and therapeutic management of sexual precocity. Arq Bras Endocrinol Metabol 2008;52:18-31.

4 Djavan B, Schlegel P, Salomon G, Eckersberger E, Sadri H, Graefen M: Analysis of testosterone suppression in men receiving histrelin, a novel GnRH agonist for the treatment of prostate cancer. Can J Urol 2010;17:5265-5271.

5 Nebesio TD, Eugster EA: Current concepts in normal and abnormal puberty. Curr Probl Pediatr Adolesc Health Care 2007;37:50-72.

6 Lewis KA, Eugster EA: Experience with the once-yearly histrelin (GnRHa) subcutaneous implant in the treatment of central precocious puberty. Drug Des Devel Ther 2009;3:1-5.

$7 \quad$ Fuqua JS: Treatment and outcomes of precocious puberty: an update. J Clin Endocrinol Metab 2013;98:2198-2207.

8 Hirsch HJ, Gillis D, Strich D, Chertin B, Farkas A, Lindenberg T, Gelber H, Spitz IM: The histrelin implant: a novel treatment for central precocious puberty. Pediatrics 2005;116:e798-e802.

9 Eugster EA, Clarke W, Kletter GB, Lee PA, Neely EK, Reiter EO, Saenger P, Shulman D, Silverman L, Flood L, Gray W, Tierney D: Efficacy and safety of histrelin subdermal implant in children with central precocious puberty: a multicenter trial. J Clin Endocrinol Metab 2007;92:1697-1704.

10 Rahhal S, Clarke WL, Kletter GB, Lee PA, Neely EK, Reiter EO, Saenger P, Shulman D, Silverman L, Eugster EA: Results of a second year of therapy with the 12month histrelin implant for the treatment of central precocious puberty. Int J Pediatr Endocrinol 2009;2009:812517.

11 Silverman LA, Neely EK, Kletter GB, Lewis K, Chitra S, Terleckyj O, Eugster EA: Long-term continuous suppression with once-yearly histrelin subcutaneous implants for the treatment of central precocious puberty: a final report of a phase 3 multicenter trial. J Clin Endocrinol Metab. In press. 
Lewis KA, Goldyn AK, West KW, Eugster EA: A single histrelin implant is effective for 2 years for treatment of central precocious puberty. J Pediatr 2013;163:1214-1216.

Davis JS, Alkhoury F, Burnweit C: Surgical and anesthetic considerations in histrelin capsule implantation for the treatment of precocious puberty. J Pediatr Surg 2014;49:807-810.

14 Monroe BJ, Fallon SC, Brandt ML: Intraoperative sonographic localization of a fractured Supprelin implant in a pediatric patient: a case report. J Pediatr Endocrinol Metab 2012;25:167-169.

Carel JC, Eugster EA, Rogol A, Ghizzoni L, Palmert MR, Antoniazzi F, Berenbaum S, Bourguignon JP, Chrousos GP, Coste J, Deal S, de VL, Foster C, Heger S, Holland J, Jahnukainen K, Juul A, Kaplowitz P, Lahlou N, Lee MM, Lee P, Merke DP, Neely EK, Oostdijk W, Phillip M, Rosenfield RL, Shulman D, Styne D, Tauber M, Wit JM: Consensus statement on the use of gonadotropin-releasing hormone analogs in children. Pediatrics 2009;123:e752-e762.

16 Houk CP, Kunselman AR, Lee PA: Adequacy of a single unstimulated luteinizing hormone level to diagnose central precocious puberty in girls. Pediatrics 2009;123:e1059-e1063.

17 Lewis KA, Eugster EA: Random luteinizing hormone often remains pubertal in children treated with the histrelin implant for central precocious puberty. J Pediatr 2013;162:562-565.

18 Neely EK, Lee PA, Bloch CA, Larsen L, Yang D, Mattia-Goldberg C, Chwalisz K: Leuprolide acetate 1-month depot for central precocious puberty: hormonal suppression and recovery. Int J Pediatr Endocrinol 2010;2010:398639.

19 Gillis D, Karavani G, Hirsch HJ, Strich D: Time to menarche and final height after histrelin implant treatment for central precocious puberty. J Pediatr 2013;163:532536.

20 Fisher MM, Lemay D, Eugster EA: Resumption of puberty in girls and boys following removal of the histrelin implant. J Pediatr 2014;164:912-916.

21 Hirsch HJ, Lahlou N, Gillis D, Strich D, Rosenberg-Hagen B, Chertin B, Farkas A, Hartman H, Spitz IM: Free alpha-subunit is the most sensitive marker of gonadotropin recovery after treatment of central precocious puberty with the histrelin implant. J Clin Endocrinol Metab 2010;95:2841-2844.

22 Thornton P, Silverman LA, Geffner ME, Neely EK, Gould E, Danoff TM: Review of outcomes after cessation of gonadotropin-releasing hormone agonist treatment of girls with precocious puberty. Pediatr Endocrinol Rev 2014;11:306-317. 
23 Schoelwer M, Donohue K, Bryk K, Didrick P, Berenbaum S, Eugster EA:

Psychological Assessment of Mothers and Their Daughters at the Time of Diagnosis of Precocious Puberty. Int J Pediatr Endocrinol 2015;in press. 